\title{
Gastric Heterotopia in the Rectum
}

\author{
Chi Young Okª, Ali Akalinª
}

\begin{abstract}
Gastric heterotopia, which is not uncommonly seen, occurs anywhere in the alimentary tract as well as in the mediastinum, scrotum and spinal cord. Gastric heterotopia in the rectum, however, is rarely reported, with only about 40 cases published in the English literature. Although it is a rare entity, it may be the source for significant problems such as rectal bleeding, abdominal and rectal pain and malignancy. Therefore, it is important to recognize this entity. Here, we report an additional case of gastric heterotopia in the rectum of 65 year-old female and review the literature.
\end{abstract}

Keywords: Gastric; Heterotopia; Rectum

\section{Introduction}

Gastric heterotopia is not uncommonly seen in the esophagus or small intestine. However, gastric heterotopia in the rectum is a rare entity. Although histopathologic finding is straightforward for correct diagnosis, gastric heterotopia is identified as polyp, diverticula or ulcer endoscopically. Awareness of this entity can direct us to correct diagnosis.

Manuscript accepted for publication December 21, 2011

${ }^{a}$ Department of Pathology, University of Massachusetts Memorial Medical Center, Worcester, Massachusetts, USA

${ }^{\mathrm{b}}$ Corresponding author: Ali Akalin, Department of Pathology, 3

Biotech, 1 Innovation Drive, Worcester, MA 01605, USA.

Email: akalina@ummhc.org

doi:10.4021/jmc484w
Here, we present a 65 year-old female with gastric heterotopia in the rectum.

\section{Case Report}

A 65 year-old female presented with bowel habit changes. The patient did not have rectal bleeding nor pain. Perianal fistula and ulceration were not identified, either. On colonoscopy, three polyps were found (4 to $8 \mathrm{~mm}$ in range) in the cecum, transverse colon and rectum, respectively. These polyps were removed with cold snare. The histopathological evaluation revealed that the polyp in the cecum was tubular adenoma and that the polyps in the transverse colon and rectum were hyperplastic polyps. An area of congested mucosa measuring approximately $3 \mathrm{~cm}$ in diameter was noted in the rectum. This patch of mucosa was demarcated by both color and texture when compared to the remainder of the rectal mucosa. Biopsies were taken for histopathological evaluation.

A sharp demarcation is seen between the rectal mucosa (left) and gastric mucosa (right) on microscopic examination (Fig. 1-A). The mucosa of the rectum shows crypt epithelia which have basally-located nuclei and purple cytoplasm. On the other hand, the mucosa on the right side shows foveolar type surface epithelium with underlying glands composed of parietal and chief cells (Fig. 1-B, C and D). Warthin-starry stain (not shown) for Helicobacter pylori did not identify microorganism in the mucosal surface.

\section{Discussion}

Gastric heterotopia has been described anywhere in the alimentary tract and even in the mediastinum [1], scrotum [2] and the spinal cord [3]. Embryologically, gastric heterotopia in the foregut is explained as the failure of developmental descent of the stomach [4]. However, gastric heterotopia distal to the foregut is explained by the pluripotential ability of primitive intestinal canal lining cells which can develop into any kind of cells in the alimentary tract [4].

Interestingly, local injury or inflammation can cause acquired changes (for example, pyloric epithelial lining) in 


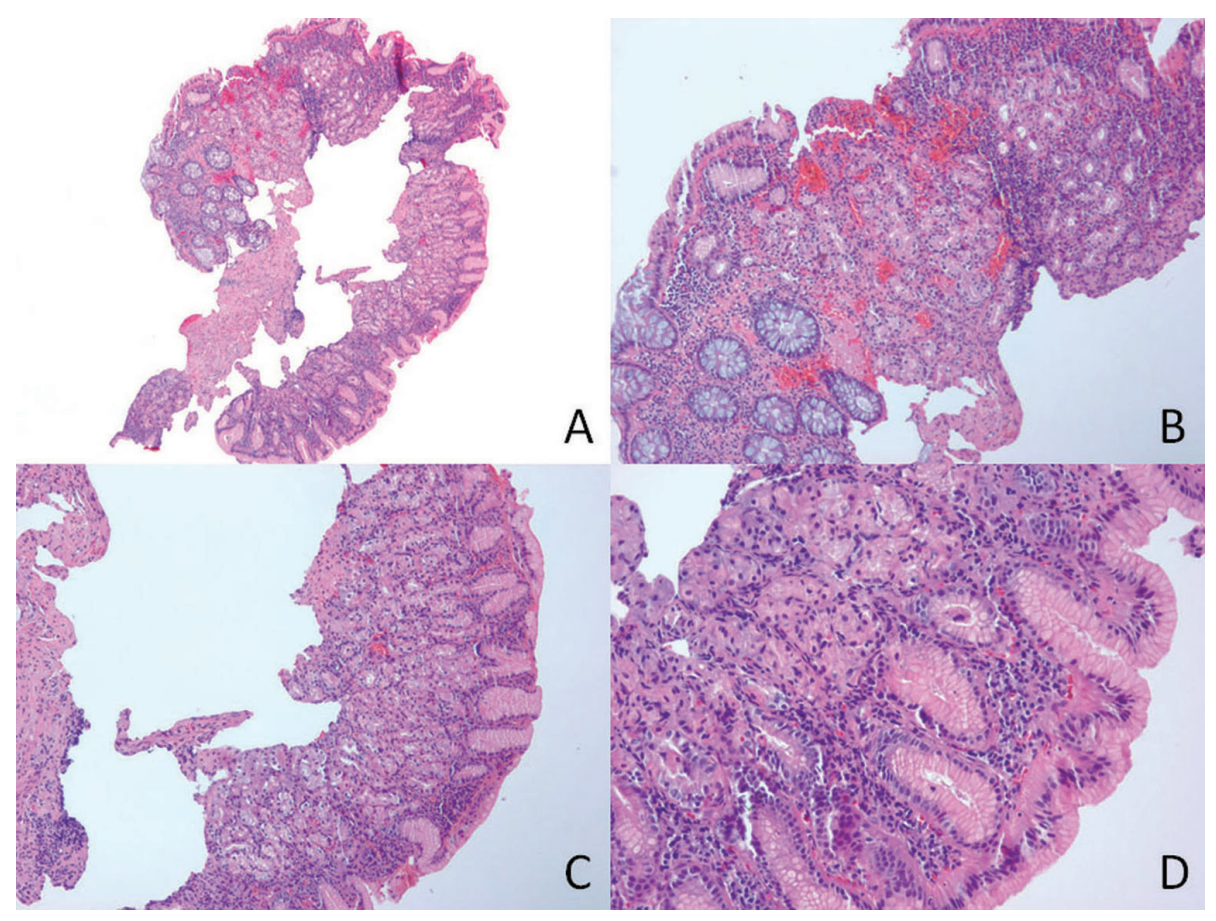

Figure 1. A: A sharp demarcation is seen between colonic mucosa (left) and gastric mucosa ( $\times 40)$; $B$ : A transition from colonic mucosal epithelium to foveolar epithelium is noticed in the left $(\times 100)$; C and D: Gastric mucosa shows foveolar epithelium with mixture of chief cells and parietal cells in the lamina propria ( $\times 100$ in $C$ and $\times 400$ in D).

some organs such as lower esophagus, duodenal bulb and gallbladder that can imitate gastric heterotopia. This type of changes is currently considered as metaplasia, that is, adaptive substitution of native cells by other cell types that are better able to withstand an adverse environment [5]. Unlike gastric heterotopia which consists of full mucosal thicknesses of specialized foveolar epithelium and gastric glands composed of chief and/or parietal cells, gastric metaplasia is of partial thickness with only foveolar epithelium and intermingles with the native tissue.

Since the first report by Ewell and Jackson [6] in 1939 in the English literature, 47 cases of gastric heterotopia in the rectum have been reported so far to the best of our knowledge [7-10]. In literature, slight male predominance is observed (male: female, 28:19) and wide range of patients' age is reported (1 day to 68 years, including current case). Majority of cases are located more than $5 \mathrm{~cm}$ above from the anal verge. However, lesions less than $2 \mathrm{~cm}$ above from the anal verge do occur.

The most common symptoms of gastric heterotopia in the rectum are painless rectal bleeding, perineal ulcer, anal pain, abdominal pain and melena in the decreasing order of frequency [7, 11-13].

Endoscopically, rectal gastric heterotopia is identified as polyp, diverticula and ulcer, but Ikematsu et al. mentioned it can mimic early depressed cancer [14]. On microscopic examination, oxyntic type mucosa is most commonly seen, followed by mixed type, indefinable type and pyloric type mucosa from which adenocarcinoma arise [4, 7].

Of note is the identification of Helicobacter pylori in gastric heterotopias in the rectum $[12,15]$. Dye et al. reported the resolution of chronic active gastritis after the eradication of Helicobacter pylori [16].

Definitive therapy is surgical excision, but $\mathrm{H} 2$ antagonist has been used to control rectal bleeding due to the multiple lesions in large intestine [13]. Symptomatic resolution almost always ensues the surgical excision and no recurrence has been reported. However, closer follow-up is recommended since the heterotopic lesion has shown neoplastic transformation in a case [4].

\section{Grant}

Not applicable.

\section{Conflict of Interest}

The authors have no conflict of interest.

\section{References}

1. Willis RA. Some unusual developmental heterotopias. Br Med J. 1968;3(5613):267-272. 
2. Khan MA, Fitzgerald RJ. Heterotopic gastric tissue in the scrotum. J Urol. 1996;155(6):2061.

3. Knight G, Griffiths T, Williams I. Gastrocystoma of the spinal cord. Br J Surg. 1955;42(176):635-638.

4. Wolff M. Heterotopic gastric epithelium in the rectum: a report of three new cases with a review of 87 cases of gastric heterotopia in the alimentary canal. Am J Clin Pathol. 1971;55(5):604-616.

5. Antonius JI, Gump FE, Lattes R, Lepore M. A study of certain microscopic features in regional enteritis, and their possible prognostic significance. Gastroenterology. 1960;38:889-905.

6. Ewell GH, Jackson RH. Aberrant gastric mucosa in the rectum with ulceration and hemorrhage. Wis Med J. 1939;38:641-643.

7. Rifat Mannan AA, Kahvic M, Bharadwaj S, Grover VK. Gastric heterotopia of the anus: report of two rare cases and review of the literature. Indian J Pathol Microbiol. 2008;51(2):240-241.

8. Ruiz Marin M, Candel Arenas MF, Parra Banos PA, Gonzalez Valverde FM, Rodenas Moncada J, Benavides Buleje JA, Martinez Crespo JJ, et al. Gastric heterotopia in the rectum: a rare cause of rectal bleeding. Am Surg. 2011;77(5):659-662.

9. Limdi JK, Sapundzieski M, Chakravarthy R, George R. Gastric heterotopia in the rectum. Gastrointest Endosc.
2010;72(1):190-191; discussion 191.

10. Yang Z, Yates T, Jhala NC. Gastric heterotopia in the rectum. Clin Gastroenterol Hepatol. 2010;8(1):A24.

11. Steele SR, Mullenix PS, Martin MJ, Ormseth E, Weppler E, Graham J, Place RJ. Heterotopic gastric mucosa of the anus: a case report and review of the literature. Am Surg. 2004;70(8):715-719.

12. Srinivasan R, Loewenstine H, Mayle JE. Sessile polypoid gastric heterotopia of rectum: a report of 2 cases and review of the literature. Arch Pathol Lab Med. 1999;123(3):222-224.

13. Murray FE, Lombard M, Dervan P, Fitzgerald RJ, Crowe J. Bleeding from multifocal heterotopic gastric mucosa in the colon controlled by an $\mathrm{H} 2$ antagonist. Gut. 1988;29(6):848-851.

14. Ikematsu H, Fu KI, Saito Y, Matsuda T, Shimoda T, Fujii T. Ectopic gastric mucosa in the rectum mimicking an early depressed cancer treated by endoscopic mucosal resection. Endoscopy. 2007;39 Suppl 1:E171-172.

15. Devereaux CE, Devereaux RG. Heterotopic gastric mucosa of the rectum with a review of the literature. J Clin Gastroenterol. 1994;19(1):41-45.

16. Dye KR, Marshall BJ, Frierson HF, Jr., Pambianco DJ, McCallum RW. Campylobacter pylori colonizing heterotopic gastric tissue in the rectum. Am J Clin Pathol. 1990;93(1):144-147. 